\title{
A estratégia de Lisboa e as suas implicações para a reforma institucional da União Europeia
}

Revista do

Serviço

Público

Ano 54

Número 3

Jul-Set 2003

\section{Maria João Rodrigues}

\section{$O$ ponto de partida de uma estratégia europeia}

O problema de partida que presidiu à preparação da Cimeira de Lisboa (março, 2000) foi o seguinte: será possível actualizar a estratégia Europeia de desenvolvimento para responder, à luz dos valores europeus, aos novos desafios decorrentes da globalização, da mudança tecnológica e do envelhecimento das populações? Um novo paradigma está a emergir em que o conhecimento e a inovação são as principais fontes de riqueza, mas também de diferença das nações, das empresas e das pessoas. A Europa está a perder terreno em relação aos EUA, mas tal não significa que os tenhamos que imitar.

Tratava-se de definir a via europeia de transição para essa economia baseada na inovação e no conhecimento, com marcas distintivas, que vão da salvaguarda da coesão social e da diversidade cultural às próprias escolhas tecnológicas. Criar uma nova plataforma competitiva é fundamental para sustentar o modelo social europeu, que terá também de ser renovado.

A resposta a essa questão exige inovações institucionais, se quisermos tirar partido do potencial deste novo paradigma, evitando, no entanto, riscos de fractura social. Inovação, por exemplo, das normas que regulam o comércio e a concorrência internacionais, os modelos sociais ou os sistemas de educação. Além disso, a inovação institucional em cada um dos Estados-Membros da União Europeia tem de internalizar o nível de integração atingido através do mercado interno e da moeda única. Isso implica certo nível de coordenação europeia, para levar a cabo reformas

Maria João Rodrigues é professora catedrática no Instituto Superior de Ciências do Trabalho e da Empresa (ISCTE) em Lisboa,

Portugal, e conselheira da Comissão Européia para as Políticas Econômicas Sociais.

Contato: mariajrodrigues@ iscte.pt 
institucionais, no respeito pelas especificidades nacionais. É necessário um sistema de governação que permita aos seus vários níveis (europeu, nacional e local) interagir.

A resposta à questão de partida exigiu uma vasta empreitada intelectual e política para a revisão da agenda política europeia e dos principais documentos de política comunitária à luz dos últimos desenvolvimentos das ciências sociais (Presidência da União Europeia, 5256/00, 2000). Foram envolvidos nessa tarefa reputados intelectuais europeus com vasta experiência nessas áreas (Presidência da União Europeia, 1999 A e B, Rodrigues, 2002). Tratava-se de identificar quais inovações institucionais podiam alterar o modo de regulação das sociedades europeias e abrirlhes nova trajectória de desenvolvimento em direcção à economia baseada no conhecimento.

Mas era preciso tornar as ideias força em decisão e acção política. Todo o desenrolar da Presidência foi arquitectado nesse sentido, tirando partido de dois conselhos europeus, 14 conselhos de ministros, sete conferências ministeriais, várias sessões no Parlamento Europeu e um fórum de alto nível, que reuniu os principais actores em nível europeu e nacional.

Estando em causa a definição de estratégia global, havia que dar o papel central ao próprio Conselho Europeu - em sinergia com as iniciativas da Comissão Europeia. A reunião do Conselho Europeu deveria ser extraordinária, concentrada apenas nesse objectivo. Deveria ter lugar suficientemente cedo para enquadrar os conselhos de ministros que lhe sucederam, mas suficientemente tarde para permitir a vasta acção de persuasão necessária para atingir um acordo. Essa acção assentou-se num conjunto de apostas ambiciosas que a Presidência assumiu o risco de propor formalmente e que se traduziu em contactos múltiplos realizados em todas as instâncias comunitárias e junto dos próprios governos, culminando com a visita do primeiro-ministro a todas as capitais da União Europeia. Um debate público permitiu também colher contributos muito diversos da sociedade civil, de todos os governos e de todas as instituições comunitárias.

As decisões da Cimeira de Lisboa ajudaram a dar a forma final ao elevado nível de consenso e mobilização criado, entretanto, fixando objectivos, calendários e métodos mais precisos, definindo mandatos para todos os conselhos de ministros envolvidos. Foi essa mola propulsora que permitiu apresentar, já no último Conselho Europeu da Feira, em junho de 2000 , um conjunto de resultados concretos que começaram a ser transpostos para o nível nacional e a ser desenvolvidos ao longo das presidências seguintes. 


\section{A estratégia de Lisboa}

O Conselho Europeu de Lisboa, de 23 e 24 de março de 2000, definiu um novo objectivo estratégico e uma estratégia global. Citando as suas Conclusões (Conselho da União Europeia, 2000-A):

"A União atribuiu-se hoje um novo objectivo estratégico para a próxima década: tornar-se no espaço económico mais dinâmico e competitivo do mundo, baseado no conhecimento, e capaz de garantir um crescimento económico sustentável, com mais e melhores empregos e com maior coesão social. A consecução desse objectivo pressupõe uma estratégia global que visa:

- preparar a transição para uma economia e uma sociedade baseadas no conhecimento, através da aplicação de melhores políticas no domínio da sociedade da informação e da I\&D, bem como da aceleração do processo de reforma estrutural para fomentar a competitividade e a inovação e da conclusão do mercado interno;

- modernizar o modelo social europeu, investindo nas pessoas e combatendo a exclusão social;

- sustentar as sãs perspectivas económicas e as favoráveis previsões de crescimento, aplicando uma adequada combinação de políticas macroeconómicas.

Essa citação é importante para clarificar que, ao contrário do que algumas vulgarizações levariam a crer, o objectivo estratégico definido em Lisboa não visa criar 'a economia mais competitiva', mas sim atingir uma combinação específica de elevada competitividade com outras características. Seria essa a especificidade da via europeia.

A estratégia de Lisboa definiu as seguintes orientações políticas:

- uma política para a sociedade da informação centrada na melhoria da qualidade de vida dos cidadãos, com aplicações concretas na educação, nos serviços públicos, no comércio electrónico, na saúde, na gestão das cidades; um novo impulso para desenvolver as tecnologias de informação nas empresas, nomeadamente o comércio electrónico e os instrumentos de gestão do conhecimento; uma ambição de desdobramento das redes avançadas de telecomunicações e de democratização do acesso à internet, por um lado, e de produção de conteúdos que valorizem o património cultural e científico europeu, por outro;

- uma política de I\&D na qual o actual programa comunitário e as políticas nacionais convergem num espaço europeu de investigação por meio da colocação em rede dos programas e das instituições de I\&D. 
Uma forte prioridade para as políticas de inovação e a criação de uma patente comunitária;

- uma política de empresa que vai para além do actual programa comunitário, combinado-o com uma coordenação das políticas nacionais, com vista à criação de melhores condições envolventes para a iniciativa empresarial - nomeadamente a simplificação administrativa, o acesso ao capital de risco ou a formação de gestores;

- reformas económicas centradas na criação de potencial de crescimento e de inovação, que dinamizam os mercados de capitais para apoiarem os investimentos de futuro, completando o mercado interno europeu através da liberalização de sectores de base, com respeito do serviço público próprio do modelo europeu;

- políticas macroeconómicas que, para além de manterem a já adquirida estabilidade macroeconómica, estimulem o crescimento, o emprego e a mudança estrutural, utilizando a política orçamental e fiscal para conferir maior prioridade ao investimento em educação, formação, investigação e inovação;

- uma renovação do modelo social europeu, tendo, por linhas de força, maior investimento nas pessoas e a activação das políticas sociais, a par de combate reforçado às novas e velhas formas de exclusão social;

- a introdução de novas prioridades para as políticas educativas nacionais: tornar as escolas em centros abertos para a educação e a formação ao longo da vida, apoiando os diferentes grupos da população, utilizando a internet e produtos multimédia; introduzir novas competências de base e estabelecer um diploma europeu para combater a iliteracia informática;

- a intensificação das políticas activas de emprego com três focos fundamentais: generalizar a formação ao longo da vida; expandir o emprego nos serviços, em particular nos serviços de apoio à família, como grande fonte de criação de empregos, de melhoria da qualidade de vida e da igualdade de oportunidades entre mulheres e homens; elevar as taxas de emprego na Europa como factor chave para a consolidação financeira dos sistemas de protecção social;

- a organização de um processo de cooperação entre EstadosMembros para a modernização da protecção social, visando fazer face a problemas comuns, como sustentar os sistemas de pensões face ao envelhecimento da população;

- a preparação de planos nacionais de combate à exclusão social nas suas várias dimensões (incluindo a educação, a saúde e a habitação), respondendo a grupos alvo específicos a cada situação nacional;

- a valorização do diálogo social na gestão da mudança e a organização de formas várias de parceria com a sociedade civil, incluindo a difusão de boas práticas das empresas com maior responsabilidade social. 
A concretização efectiva de uma estratégia requer um motor político: um centro de governação em nível europeu com capacidade para coordenar as várias políticas e para as adaptar a cada contexto nacional. As decisões de Lisboa reforçaram esse centro de governação de três formas:

- em primeiro lugar, conferindo ao Conselho Europeu um maior papel de coordenador das várias formações do Conselho de Ministros, que passará a dedicar a sua reunião de primavera à monitoragem dessa estratégia;

- em segundo lugar, as grandes orientações de política económica passarão a melhorar a sinergia entre políticas macroeconómicas, estruturais e de emprego;

- em terceiro lugar, com vista a complementar os instrumentos legislativos, a União adoptou um método aberto para a coordenação entre Estados-Membros, que começou já a ser aplicado a diferentes políticas, intensificando a tradução das prioridades europeias para as políticas nacionais.

O método aberto de coordenação foi elaborado após uma reflexão sobre governação destinada a definir métodos para desenvolver a dimensão europeia. Essa elaboração pode resumir-se da seguinte forma.

A construção política da Europa é uma experiência única. O seu sucesso tem dependido da habilidade de combinar coerência com respeito pela diversidade e eficácia com legitimidade democrática. Isso implica utilizar métodos políticos diferentes consoante as políticas e os vários processos institucionais. Por boas razões, vários métodos têm sido concebidos e situam-se entre a integração pura e a cooperação leal. Assim, temos:

- a política monetária é uma política única no seio da zona Euro;

- a construção do mercado interno europeu é baseada numa lógica de harmonização e em políticas únicas de concorrência e de comércio externo;

- as políticas orçamentais nacionais são coordenadas em nível europeu com base em critérios e regras estritamente predefinidos.

No entanto, há certas políticas mais vocacionadas para a criação de novas competências e capacidades para responder às mudanças estruturais. Envolvem uma aprendizagem mais rápida e a descoberta de soluções apropriadas. Essas políticas resultaram na formulação de linhas directrizes estratégicas em nível europeu, com vista a fazer face à mudança estrutural, que são também mais abertas à diversidade nacional.

Na realidade, a principal fonte de inspiração do método aberto de coordenação foi o processo do Luxemburgo para a estratégia europeia 
do emprego. Esse método foi criado para suplantar uma importante dificuldade política identificada na preparação do Conselho Europeu do Luxemburgo sobre o emprego, em 1997, na medida em que não era possível adoptar uma meta comum para a redução do desemprego, como contrapartida das metas comuns para a redução da inflação, do déficit e da dívida. No entanto, sob a pressão política dessa Cimeira, foi possível adoptar linhas directrizes qualitativas comuns, efectuando algumas escolhas políticas para reformar os mercados de trabalho europeus. Depois disso, foi organizado um processo no qual os Estados-Membros se emulam uns aos outros na sua aplicação, estimulando a troca de boas práticas e definindo metas específicas, tendo em conta as características nacionais. A Comissão Europeia apresenta a proposta de linhas directrizes europeias, organiza o seu acompanhamento e pode fazer recomendações aos EstadosMembros. Não obstante algumas dificuldades, os resultados obtidos têm sido estimulantes e encorajadores, e o impacte dos actuais planos nacionais de emprego adoptados por todos os Estados-Membros são disso prova.

\section{O método aberto de coordenação}

Três anos volvidos, a definição do método aberto de coordenação foi expressamente concebida durante a preparação do Conselho Europeu de Lisboa, a fim de desenvolver a dimensão europeia em novas áreas políticas, nomeadamente a sociedade da informação, a investigação, a inovação, a política de empresa, a educação e o combate à exclusão social. Depois de profundas discussões levadas a cabo pela Presidência com os governos, a Comissão Europeia, o Parlamento Europeu e os parceiros sociais, esta Cimeira adoptou formalmente esse método nos termos seguintes (Conclusões da Presidência, 2000).

\section{Aplicação de um novo método aberto de coordenação}

"A consecução do objectivo estratégico será facilitada pela aplicação de um novo método aberto de coordenação conduzindo à divulgação de melhores práticas e favorecendo uma maior convergência no que respeita aos principais objectivos da UE. Esse método, que foi delineado para ajudar os Estados-Membros a desenvolverem progressivamente as suas próprias políticas, implica:

- que sejam definidas, para a União, orientações combinadas com calendários específicos para a consecução dos objectivos nelas fixados a curto, médio e longo prazo; 
- que sejam estabelecidos, sempre que necessário, indicadores quantitativos e qualitativos e benchmarks entre os melhores do mundo, adequados às necessidades dos diferentes Estados-Membros e sectores como um método de comparação das melhores práticas;

- que essas orientações europeias sejam traduzidas em políticas nacionais e regionais, por via da definição de metas específicas e da adopção de medidas, tendo em conta as diferenças nacionais e regionais;

- que se proceda periodicamente à monitorização, à avaliação e à análise pelos homólogos, organizadas como um processo de aprendizagem recíproca.

Será aplicada uma abordagem plenamente descentralizada consentânea com o princípio da subsidiariedade, em que a União, os Estados-Membros, as instâncias regionais e locais, bem como os parceiros sociais e a sociedade civil, estarão activamente associados, mediante o recurso a formas variáveis de parceria. A Comissão Europeia, através de um trabalho em rede com os diversos fornecedores e utilizadores, designadamente os parceiros sociais, as empresas e as ONGs, elaborará um método de benchmarking das melhores práticas de gestão da mudança.

Uma última questão merece ser abordada. Como poderia a aplicação do método aberto de coordenação ser coordenada nas diferentes áreas políticas? Segundo as conclusões do Conselho Europeu de Lisboa, no seu parágrafo $36^{\circ}$ :

"Estas melhorias serão potenciadas pelo propósito de o Conselho Europeu assumir um significativo papel de orientação e coordenação com vista a assegurar a coerência global e a monitorização efectiva da progressão para o novo objectivo estratégico. Assim, o Conselho Europeu realizará anualmente, na primavera, uma sessão dedicada às questões económicas e sociais. Consequentemente, deverão organizar- se os trabalhos tanto a montante como a jusante de tal sessão. O Conselho Europeu convida a Comissão a elaborar anualmente um relatório de síntese sobre os progressos efectuados, com base em indicadores estruturais a serem acordados, referentes ao emprego, à inovação, à reforma económica e à coesão social".

Assim, o Conselho Europeu deveria conduzir e monitorar os resultados alcançados pelo método aberto de coordenação nas diferentes áreas, com base em iniciativas regulares da Comissão Europeia. Isso requer duas capacidades distintas por parte dos membros do Conselho Europeu:

- definir as orientações gerais para as diferentes áreas políticas, a fim de organizar o trabalho das diferentes formações do Conselho, a montante e a jusante;

- assegurar a sua aplicação em nível europeu e nacional. 
No seguimento das Conclusões da Cimeira de Lisboa, esse método está agora a ser aplicado a diferentes áreas políticas:

- na sociedade da informação, o Plano de Acção eEurope apresenta prioridades claras, boas práticas, indicadores e responsabilidades em nível europeu e nacional;

- na política de empresa, um exercício de benchmarking baseado em indicadores comuns está a ser aplicado, envolvendo as políticas nacionais;

- no processo de Cardiff para as reformas económicas, estão a ser identificados indicadores estruturais com vista a reforçar as prioridades definidas para sustentar os relatórios nacionais;

- na política de educação, para além da definição de objectivos e indicadores comuns, está a ter lugar um debate com vista à aplicação de prioridades comuns e boas práticas, utilizando relatórios nacionais;

- na política de investigação, está-se a progredir no sentido do mapeamento das redes de I\&D e da melhoria da coordenação, assim como na organização de um exercício de benchmarking com base em indicadores comuns;

- na inclusão social, estão a ser identificados prioridades e indicadores, depois de terem sido adoptados objectivos comuns, com vista à preparação de planos nacionais.

Conforme solicitado pelas Conclusões da Cimeira de Lisboa, foi adoptada pelo Conselho Europeu de Nice uma bateria de 35 indicadores comuns, que cobre as áreas de emprego, reformas económicas, inovação e coesão social e que é parte integrante do Relatório de Síntese apresentado pela Comissão Europeia ao Conselho Europeu da Primavera. A União Europeia pode, doravante, fazer o acompanhamento não só da convergência nominal, mas também da convergência real.

O método aberto de coordenação foi já sujeito a numerosos debates em nível político, tendo também suscitado os primeiros contributos por parte de investigadores em ciências sociais. Este debate emergente levame a contribuir com alguma elaboração e clarificação ex post. Estes comentários têm também em conta desenvolvimentos teóricos recentes.

Alguns comentários gerais impõem-se a fim de clarificar o método em si (Presidência da União Europeia, 9088/00, 2000):

- o objectivo do método aberto de coordenação não é definir um ranking geral dos Estados-Membros em cada política, mas sim organizar um processo de aprendizagem em nível europeu, com vista a estimular a troca e a emulação de boas práticas e a auxiliar os Estados-Membros a melhorar as suas políticas nacionais;

- o método aberto de coordenação utiliza o benchmarking como técnica, mas vai para além do simples exercício de benchmarking. Cria uma dimensão europeia e opera escolhas políticas por meio da definição 
de linhas directrizes europeias, e encoraja a gestão por objectivos por meio da adaptação dessas linhas directrizes europeias à diversidade nacional;

- o método aberto de coordenação é uma forma concreta de desenvolver a governação moderna, utilizando o princípio da subsidiaridade;

- o método aberto de coordenação pode promover a convergência em relação ao interesse comum e a prioridades comuns acordadas, no respeito pelas diversidades nacionais e regionais. Trata-se de um método inclusivo para aprofundar a construção europeia;

- o método aberto de coordenação deve ser combinado com os outros métodos existentes, dependendo do problema a tratar. Estes métodos vão da harmonização à cooperação. O método aberto de coordenação ocupa ele próprio uma posição intermédia nesta escala de diferentes métodos. Vai para além da cooperação intergovernamental e constitui instrumento de integração a juntar a um conjunto mais geral de instrumentos;

- a Comissão Europeia pode representar um papel crucial enquanto catalisador nos diferentes estádios do método aberto de coordenação, nomeadamente por meio: da apresentação de propostas para linhas directrizes europeias, da organização de trocas de boas práticas, da apresentação de propostas de indicadores, do apoio à monitoragem e à revisão pelos pares;

- o método aberto de coordenação pode igualmente tornar-se um importante instrumento para melhorar a transparência e a participação democrática.

O método aberto de coordenação é chamado "aberto" por várias razões:

- porque as linhas directrizes europeias e a sua prioridade relativa podem ser adaptadas ao nível nacional;

- porque as boas práticas deveriam ser avaliadas e adaptadas no seu contexto nacional;

- porque existe uma distinção clara entre indicadores de referência a adoptar em nível europeu e metas concretas a adoptar pelos EstadoMembro para cada indicador, tendo em conta o seu ponto de partida. Por exemplo, os indicadores comuns podem ser a ratio entre investimento em I\&D e o PIB, ou a participação feminina, mas o objectivo deverá ser diferente para cada Estado-Membro. Isso significa que a monitoragem e a avaliação devem-se basear nos progressos alcançados ou nos resultados relativos;

- porque a monitoragem e a avaliação devem ter em conta o contexto nacional numa abordagem sistémica; 
- finalmente, porque o desenvolvimento desse método nos seus diferentes estádios deve estar aberto à participação dos vários actores da sociedade civil. A parceria é um instrumento da governação moderna.

\section{Balanço da aplicação da estratégia de Lisboa}

Num balanço geral da aplicação da estratégia de Lisboa, ressaltam-se algumas tendências:

- a estratégia de Lisboa tem sido uma referência central no desenvolvimento e na renovação das políticas económicas e sociais da UE;

- a Comissão Europeia incorporou sistematicamente essa estratégia no seu programa de trabalho e apresentou uma longa lista de propostas em sintonia com a agenda política e as linhas directrizes definidas em Lisboa;

- o método aberto de coordenação, proposto por essa estratégia, está a ser estendido às políticas para a sociedade da informação, investigação, inovação, educação, exclusão social e protecção social;

- o Conselho, nas suas várias formações, tem vindo a aplicar essa agenda, com base nas propostas acima referidas;

- uma parte das linhas directrizes definidas em nível europeu está actualmente a ser adaptada pelos Estados-Membros ao nível nacional, embora a ligação com o nível europeu não seja sempre explicitada.

Impõe-se uma referência especial aos progressos mais relevantes, que apresentamos a seguir:

- O Plano eEurope para a sociedade da informação alcançou um nível considerável de aplicação em nível europeu e nacional. Já foi lançada a nova edição desse plano para 2003-2005.

- Estão em curso as linhas directrizes e instrumentos para a construção do Espaço Europeu de Investigação com o $6^{\circ}$ Programa-Quadro de investigação e desenvolvimento para 2002-2006.

- Foram apresentados pela Comissão Europeia desenvolvimentos mais ambiciosos para a política de inovação, que foram adoptados pelo Conselho.

- O Programa Plurianual para a empresa, aprovado em 2001, e a Carta Europeia das pequenas empresas constituem a base de um exercício de benchmarking em curso, no quadro da política de empresa.

- Tanto os relatórios nacionais como o relatório de síntese sobre as reformas económicas, denominado processo de Cardiff, e o Programa de Trabalho para o Mercado Interno fazem referência à realização da estratégia de Lisboa. Foi alcançado um progresso significativo com a 
aprovação do estatuto da sociedade europeia, a comunicação sobre serviços de interesse geral, a redução dos auxílios de Estado e a liberalização da indústria das telecomunicações e dos sectores da energia.

- A reforma e a integração dos mercados financeiros, com base em relatórios elaborados pela Comissão Europeia e pelo Comité de Sábios, está actualmente em curso.

- A Iniciativa Inovação 2000, lançada pelo Banco Europeu de Investimento, apoiou um vasto leque de projectos nos Estados-Membros.

- Foi alcançado um acordo relativo à directiva sobre tributação da poupança, na seqüência da matriz aprovada pelo Conselho Europeu de Santa Maria da Feira.

- Em termos de política de educação, assiste-se a uma renovação considerável na abordagem baseada no método aberto de coordenação e estão a ser definidos objectivos mais ambiciosos para a aprendizagem ao longo da vida.

- O pacote do emprego aprovado no processo do Luxemburgo inclui uma renovação significativa nas linhas directrizes, com base na estratégia de Lisboa.

- Quanto à política de protecção social, a Comissão, o Grupo de Alto Nível para a Protecção Social e o Comité de Política Económica estão a desenvolver um trabalho conjunto muito relevante sobre os problemas e a aplicação das estratégias de reforma.

- A política de combate à exclusão social conheceu talvez o progresso mais rápido, como o prova o facto de a lista de objectivos apropriados aprovada pelo Conselho ter sido transformada em planos nacionais de combate à exclusão social, em 2001.

- Depois de um complexo debate, a Agenda de Política Social foi aprovada no Conselho Europeu de Nice, definindo as prioridades da política social para os próximos cinco anos.

- As diferentes formações do Conselho e os comités continuam a identificar indicadores relevantes a bom ritmo. A lista de 35 indicadores estruturais prioritários para o emprego, reformas económicas, inovação e coesão social, aprovada na Cimeira de Nice, foi incorporada no Relatório de Síntese regularmente apresentado pela Comissão Europeia ao Conselho Europeu da Primavera.

- As questões chave para as orientações gerais de política económica foram afinadas com a estratégia de Lisboa sob a coordenação do Ecofin e contemplam uma melhor articulação com a estratégia de Lisboa, embora ainda haja muito que progredir nessa matéria. Está também em discussão uma proposta da Comissão Europeia para o reforço da coordenação das políticas económicas no seio da zona Euro. 
- A dimensão ambiental foi acrescentada, pelo Conselho Europeu de Estocolmo, em 2001, às dimensões económica e social definidas em Lisboa, munindo a União Europeia de uma estratégia polivalente para o desenvolvimento sustentável.

No entanto, e não obstante todos esses progressos, continua a haver deficiências na aplicação da estratégia, conforme identificadas em detalhe pelo relatório de síntese apresentado pela Comissão. Um teste decisivo à eficácia da estratégia de Lisboa é a capacidade de os Estados-Membros aplicarem-na em nível nacional.

Foi necessário um esforço de síntese para preparar a estratégia de Lisboa. Esse tipo de esforço é também necessário para fazer o seu acompanhamento (como o demonstra cada Conselho Europeu da Primavera), e, ainda mais, para fazer a sua avaliação. De forma muito preliminar, tentaremos identificar algum dos progressos já alcançados, assim como algumas das dificuldades e desafios com os quais nos defrontamos.

Começaremos pela sociedade da informação, que nos parece fornecer um dos melhores exemplos dos progressos concretos que estamos a conhecer por agora. Foi levada a cabo uma abordagem inovadora para desenvolver a sociedade da informação, com base na expansão das diferentes utilizações da internet e na preparação das pessoas, das empresas e dos serviços públicos. O Plano de Acção e Europe deu um impulso aos planos nacionais para a sociedade da informação, e o exercício de benchmarking está a progredir de forma real no terreno. Já foi apresentado um segundo plano europeu para os próximos três anos, focalizado no círculo virtuoso que pode ser criado pela banda larga. No entanto, uma sociedade baseada no conhecimento é mais do que a sociedade da informação e ainda subsistem muitas áreas nas quais a Europa continua atrasada em relação aos Estados Unidos.

Na política de investigação, foi já lançado o 6º Programa-Quadro cujo objectivo é criar um espaço europeu de investigação, criando redes de excelência e melhorando a coordenação dos programas nacionais. Recentemente, no Conselho Europeu de Barcelona, foi definida uma meta ambiciosa: até 2010, uma média de 3\% do PIB europeu deverá ser investida em I\&D, combinando investimento público e privado. E aqui coloca-se uma dificuldade clara: para atingir essa meta, é crucial desenvolver uma estratégia ambiciosa para a economia baseada no conhecimento com uma dimensão europeia relevante. Essa é uma questão não só para as instituições de I\&D, mas também para as empresas.

É por essa razão que as políticas para a inovação e a empresa se vão tornar cruciais. Isso significa reduzir a burocracia, estimular o empreendedorismo, reduzir o défice de competências, reforçar a interface entre as instituições de I\&D e as empresas, desenvolver parcerias para a 
inovação. O método aberto de coordenação pode impulsionar esse

processo. Podemos ter reunido as condições políticas para um passo à frente: desenvolver as políticas nacionais para o empreendedorismo e a inovação, adaptando as linhas directrizes europeias já identificadas em nível europeu. Isso pode fazer a diferença em termos de competitividade europeia.

O aval recente ao Projecto Galileo responde a uma ambição europeia de promover empreendimentos tecnológicos de ponta com efeitos de spill-over muito relevantes. Em contraste, o debate em curso sobre a patente comunitária ainda está entravado por interesses nacionais demasiado particulares.

O ambiente para a inovação pode também ser fortemente melhorado pela abertura dos mercados, a integração dos mercados financeiros e a disponibilização de capital de risco em nível europeu. É por isso que a decisão recente do Conselho Europeu de Barcelona no sentido de liberalizar o mercado da energia e de aprovar o Relatório Lamfalussy sobre mercados financeiros é tão importante. A decisão do Conselho Europeu provou também que é possível combinar liberalização e serviços de interesse público. O sector das telecomunicações apresenta já alguns exemplos, mas é necessária uma discussão mais aprofundada para se encontrarem soluções concretas em cada sector.

No domínio social, têm-se registado também progressos relevantes. Na seqüência da experiência do processo do Luxemburgo para as políticas de emprego, o método aberto de coordenação está agora a ser aplicado na política para a inclusão social: todos os Estados-Membros têm planos de acção nacionais de combate à exclusão social nas suas velhas e novas formas, como o risco de fractura social. O mesmo processo está em desenvolvimento na protecção social, apesar das diversidades nacionais nessa matéria, a fim de reformar o sistema de pensões para responder às tendências do envelhecimento. Problemas complexos de sustentabilidade terão, contudo, de ser ainda tratados. De forma mais lata, a Agenda para a Política Social está a tratar de problemas diversificados relativos à reforma do modelo social europeu.

Até na política de educação, um domínio por excelência da soberania nacional, foi reconhecido que os Estados-Membros enfrentam um conjunto de problemas comuns, que justificaram a identificação de um conjunto de objectivos comuns relativos à qualidade, ao acesso, às competências de base, à aprendizagem ao longo da vida. Os Estados-Membros comprometeram-se a reportar regularmente aos progressos registrados no quadro do método aberto de coordenação, que está a ser organizado nessa área. Os parceiros sociais estão também em sintonia com esses esforços, como demonstra o seu recém-aprovado quadro para a acção na educação ao 
longo da vida. Mas deparamo-nos ainda com muitas dificuldades no caminho para a criação da chamada sociedade aprendente: como repartir os custos deste investimento? Como deverá evoluir a gestão social do tempo? Como podem as escolas transformar-se em centros abertos de aprendizagem?

Para concluir, gostaria de apontar algumas questões chave a serem tratadas no desenvolvimento futuro da estratégia de Lisboa. Esse exercício deveria ser amplificado por uma maior interacção entre responsáveis políticos e investigadores.

Em primeiro lugar, as implicações do alargamento. A estratégia de Lisboa deveria ser encarada pelos países candidatos como oportunidade para recuperar o atraso, e não como dificuldade adicional. É essa a razão pela qual o método aberto de coordenação baseia-se em prioridades e indicadores comuns, mas também de parte do princípio que as metas concretas são definidas pelos próprios Estados-Membros, de acordo com diferentes pontos de partida.

Isso significa que a estratégia de Lisboa e o método aberto de coordenação fornecem também um quadro para a convergência real e para o re-equacionamento das políticas de coesão económica e social.

As políticas macroeconómicas, nomeadamente a política orçamental e fiscal, deveriam, no quadro do Pacto de Estabilidade, ser mais sofisticadas para promover a mudança estrutural. Por exemplo, a despesa pública e os incentivos fiscais deveriam focalizar-se mais no apoio às infra-estruturas do conhecimento, da inovação e da educação ao longo da vida. Necessitamos de critérios mais precisos para avaliar a qualidade das finanças públicas. É também importante lembrar que a estratégia de Lisboa visa ao desenvolvimento do potencial e da taxa de crescimento de forma sustentável. Com uma taxa mais elevada de crescimento sustentável, tornar-se-á mais fácil cumprir os critérios de estabilidade.

Precisamos de desenvolver uma abordagem polivalente para a economia e a sociedade baseadas no conhecimento. É crucial para o sucesso da estratégia de Lisboa e pode fazer a diferença na via europeia. Precisamos de criar novos factores competitivos para sustentar a nossa qualidade de vida. O conhecimento é mais do que informação e os processos de gestão do conhecimento deveriam ser aperfeiçoados nas empresas, escolas, instituições de I\&D e serviços públicos. A nossa diversidade cultural é um activo porque nos permite compreender outras culturas e pode dar-nos um papel mais eficaz num mundo globalizado.

A principal preocupação em relação à estratégia de Lisboa prendese com o respeito pelos objectivos já fixados, com a sua tradução para o nível nacional e a sua conversão numa agenda para a iniciativa dos diferentes actores. 


\section{Algumas implicações da estratégia de Lisboa para a reforma institucional da União Europeia}

Uma última palavra sobre as implicações da agenda de Lisboa para a reforma institucional da União Europeia. Tendo em conta a estrutura de base do tratado apresentada pelo Praesidium da Convenção, as principais implicações parecem ser as seguintes em cada título proposto:

a) Os objectivos da União:

- manter o equilíbrio entre as três dimensões do desenvolvimento sustentável: económica, social e ambiental;

- promover o pleno emprego;

- combinar coerência europeia acrescida com o respeito pela diversidade nacional.

b) A cidadania europeia:

- as políticas abrangidas pela estratégia de Lisboa podem contribuir para conferir um conteúdo concreto aos direitos incluídos na Carta dos Direitos Fundamentais.

c) As competências e as acções da União:

- a aplicação da estratégia de Lisboa baseia-se na construção de um sistema de governação a vários níveis, aliado a um governo europeu reforçado;

- a questão chave é a criação de uma sinergia positiva na interacção entre os diferentes níveis (europeu, nacional e local);

- isso requer uma boa conjungação, em cada política, de competências exclusivas da União (predominantes nas políticas do comércio, concorrência e monetária), competências partilhadas (predominantes nas políticas macroeconómica, ambiental, de investigação e de emprego) e competências de apoio da União, por meio da promoção e da coordenação das políticas nacionais (competências predominantes nas políticas de educação, inovação, protecção social, inclusão social).

d) As instituições da União:

- o governo europeu deveria basear-se numa sinergia reforçada entre Comissão e Conselho;

- o direito exclusivo de iniciativa pertence à Comissão europeia, como se pode constatar na apresentação do Relatório de Síntese, seguido pela apresentação de linhas directrizes para as diferentes políticas;

- ao Conselho Europeu deve caber um papel estratégico de liderança, coordenação-geral das várias políticas e da sua aplicação em nível nacional; o Conselho Europeu da Primavera focaliza a estratégia de Lisboa, assegurando a coordenação do ciclo anual das políticas económicas e sociais; 
- a distinção entre conselho legislativo e conselho executivo pode ser muito útil;

- as formações do conselho relevantes para a estratégia de Lisboa são as seguintes: Ecofin, emprego e política social, competitividade, ambiente, educação, transportes e telecomunicações. É particularmente importante a criação de um Conselho de Assuntos Gerais, composto por ministros dos Assuntos Europeus, reportando-se aos primeiros-ministros e capazes de assegurar a coordenação das várias políticas, de preparar o acompanhamento das orientações do Conselho Europeu e de proceder a esse acompanhamento;

- o Parlamento Europeu deveria estar envolvido de forma mais sistemática no acompanhamento da estratégia de Lisboa, assim como os Parlamentos nacionais; isso requer uma melhor coordenação entre as diferentes comissões parlamentares.

e) A aplicação das competências e das acções da União são as seguintes:

- a estratégia de Lisboa deveria fazer uma utilização plena dos diferentes instrumentos de que dispõe a União: legislativos (leis e leisquadro), normas de aplicação e instrumentos de apoio para promover ou coordenar as políticas nacionais, como é o caso do método aberto de coordenação;

- o voto por maioria qualificada deveria ser estendido a um maior número de áreas;

- a coordenação das diferentes políticas deveria basear-se num calendário para adopção, aplicação e avaliação;

- o método aberto de coordenação deveria ter uma definição mais clara e geral no tratado, compatível com alguma adaptação a cada política específica. As principais componentes deste método que deveriam ser referidas no tratado são as seguintes:

- linhas directrizes e objectivos comuns adoptados em nível europeu;

- a sua adaptação às políticas nacionais e regionais;

- um processo de monitoragem com uma revisão pelos pares com base em indicadores comuns e na identificação de boas práticas;

- a iniciativa à Comissão Europeia, com validação pelo Conselho e pelo Parlamento Europeu;

- um processo que permita envolver os parceiros sociais e os outros actores da sociedade civil.

f) A vida democrática da União:

- o método aberto de coordenação reforça os princípios da democracia participativa, da parceria e da partilha de responsabilidades;

- os papéis visíveis do diálogo civil e em diálogo social deveriam ser clarificados; 
- deveria ser criado um órgão de concertação social tripartida a um nível estratégico.

g) As finanças da União:

- a coordenação das políticas nacionais tem um efeito multiplicador no orçamento da União;

- o orçamento da União deveria envolver os meios para sustentar as competências da União no âmbito da estratégia de Lisboa;

- a estratégia de Lisboa deve também ser entendida como alavanca para a convergência real entre os Estados-Membros.

h) A acção externa da União:

- uma acção externa da União mais coordenada é crucial para colher todos os benefícios da estratégia de Lisboa, entendida como resposta próactiva à globalização.

Finalmente, a identificação dos instrumentos a utilizar em cada política deveriam definir um ‘chão' e não um 'tecto'. Deveriam ser permitidos novos desenvolvimentos, estabelecendo um conceito evolutivo da arquitectura política que sustenta a Constituição europeia. Desenvolver essa interacção entre a evolução das políticas e as reformas institucionais tem sido a arte essencial da construção europeia. 


\section{Geral}

Council of the European Union. Conclusions of the Brussels European Council, Council of the European Union SN 100/03, 20-21 March 2003.

. Conclusions of the Lisbon European Council, Council of the European Union SN 100/00, 23-24 March 2000, (2000-A).

European Commission. Communication from the Commission: Realising the European Union's potential: consolidating and extending the Lisbon Strategy, COM (2001) 79, 08.02.2001.

. Communication: Choosing to grow: Knowledge, Innovation and Jobs in a Cohesive Society - Report to the Spring European Council, 21 March 2003 on the Lisbon strategy of economic, social and environmental renewal, COM (2003) 5 final, 14.01.2003

. Contribution to the Spring European Council in Barcelona: The Lisbon Strategy - Making Change happen, COM (2002) 14 final, 15.01.2002.

. Growth, competitiveness, employment - The challenges and ways forward into the 21st Century, Luxembourg: Office for Official Publications of the European Communities, (1994).

European Parliament. Report on the Spring 2001 European Council: The Lisbon process and the path to be followed, A5-0034/2001, 30.01.2001.

Presidency Conclusions (Barcelona European Council), Ref. Council of the European Union SN 100/02

Presidency Conclusions (Stockholm European Council), Ref. Council of the European Union SN 200/01

Presidency of THE EUROPEAN Union. Document from the Presidency - "Employment, Economic Reforms and Social Cohesion - Towards a Europe based on innovation and knowledge”, Council of the European Union 5256/00, 12.01.2000.

9088/00, 14.06.2000.

Note on the ongoing experience of the open method of co-ordination,

Rodrigues, Maria João (coord.) with the collaboration of Robert Boyer, Manuel Castells, Gøsta Esping-Andersen, Robert Lindley, Bengt-Åke Lundvall, Luc Soete and Mario Telò, The New Knowledge Economy in Europe - a strategy for international competitiveness and social cohesion, Cheltenham: Edward Elgar, (2002-A).

\section{Política para a sociedade de informação}

European Commission, eEurope 2002. An Information Society for all, Action Plan prepared for Feira European Council, 14.06.00.

European Commission, eEurope 2005. An information society for all-Action Plan to be presented in view of the Sevilla European Council, Ref. COM(2002) 263 final, 28.05.2002. 


\section{Política de investigação}

European Commission. Communication from the Commission Investing in Research: an Action Plan for Europe, COM (2003) 226 final, 30.04.2003.

Communication: Making a reality of the European Research Area: Guidelines for EU research activities (2002-2006), COM (2000) 612 final, 04.10.2000. . Communication: Towards a European Research Area, COM (2000)

06, 18.01.2000.

European Parliament. Council of the European Union, Decision concerning the 6th Framework Programme of the European Community for Research, Technological development and demonstration activities, contributing to the creation of the European Research Area and to innovation (2002-2006), PE-CONS 3635/02, 27.06.2002.

\section{Política de inovação}

European Commission. Communication from the Commission Innovation Policy: Updating the Union's Approach in the Context of the Lisbon Strategy, COM (2003) 112 final, 11.03.2003.

. Communication from the Commission: Industrial Policy in an Enlarged Europe, COM (2002) 714 final, 11.12.2002.

. Communication: Innovation in a Knowledge-driven economy, COM

$567,20.09 .2000$

\section{Política de empresa}

EUROPEAN COMMISSION. Benchmarking Enterprise Policy - First results from the Scoreboard, SEC (2000) 1842, 27.10.2000.

. Green Paper on Entrepreneurship in Europe, COM (2003) 27 final,

21.01.2003.

\section{Política para o mercado interno}

European Commission. Financial Services Action Plan - Second Progress Report (2000), COM (2000) 336 final, 30.05.2000.

\section{Políticas macroeconómicas}

European Commission (2003-E), Communication from the Commission on the Broad Guidelines of the Economic Policies of the Member States and the Community (for the 2003-2005 period), COM (2003) 170 final, 08.04.2003.

EUROPEAN INVESTMENT BANK (2001). Innovation 2000 Initiative: From Lisbon to Stockholm: the EIB's i2i one year after - Progress and perspectives in implementation, March 2001.

\section{Política de educação}

Council of the European Union. Declaration of the European Ministers of Vocational Education and Training, and the European Commission, convened in Copenhagen on 29 
and 30 November 2002, on enhanced European cooperation in vocational education and training - “The Copenhagen Declaration”, Copenhagen, 30.11.2002.

European Commission. Communication from the Commission eLearning - Designing tomorrow's education, COM (2000) 318 final, 24.05.2000.

. Communication from the Commission: the role of the universities in the Europe of knowledge, COM (2003) 58, 05.02.2003. . Report on the future objectives of education systems, COM (2001) 59

final, 31.01.2001.

\section{Política de emprego}

EuROPEAN COMmission. Joint Employment report 2002.

. Proposal for a Council decision on Guidelines for the Employment Policies of the Member States, COM (2003) 176 final, 08.04.2003.

\section{Política social}

Council of THE EURopean Union. Fight against poverty and social exclusion - Definition of objectives for Nice European Council - Political agreement, Ref. 12189/00, 10.10.2000. European Commission. Social Policy Agenda, COM (2000) 379 final, 28.06.2000.

SPC and EPC (2001), Quality and Viability of Pensions, Joint Report by the Social Protection Committee and the Economic Policy Committee on Objectives and Working Methods in the Area of Pensions: Applying the Open Method of Co-ordination, November 2001.

\section{Política para o desenvolvimento sustentável}

European Commission. Communication from the Commission: A Sustainable Europe for a Better World: a European Union Strategy for Sustainable Development, COM (2001) 264 final, 15.05.2001.

\section{Internet}

www.europa.eu.int

www.europa.eu.int/comm/lisbon_strategy/index_en.html

www.theepc.be

www.cer.org.uk

www.notre-europe.asso.fr 


\section{A estratégia de Lisboa e as suas implicações para a reforma institucional da União Européia}

\section{Maria João Rodrigues}

Como manter a estratégia européia de desenvolvimento atualizada, e à luz dos valores europeus, para reagir aos novos desafios decorrentes da globalização, da mudança tecnológica e do envelhecimento das populações? Um novo paradigma emerge, em que o conhecimento e a inovação são as principais fontes de riqueza e também de diferenças entre as nações, as empresas e as pessoas.

Era preciso definir a via européia de transição para essa economia baseada na inovação e no conhecimento, com marcas distintas que vão da salvaguarda da coesão social e da diversidade cultural às próprias escolhas tecnológicas. Criar uma nova plataforma competitiva é fundamental para sustentar o modelo social europeu, que também deverá ser renovado.

Este artigo nos traz o debate dos países membros da União Européia que precedeu a Cimeira de Lisboa (23 e 24 de Março de 2000).

\section{La estrategia de Lisboa y sus implicaciones para la reforma institucional de la Unión Europea}

Maria João Rodrigues

¿Cómo mantener la estrategia europea de desarrollo actualizada, y a la luz de los valores europeos, para reaccionar a los nuevos desafíos decurrentes de la globalización, de cambios tecnológicos y del envejecimiento de las poblaciones? Un nuevo paradigma emerge, en que el conocimiento y la innovación son las principales fuentes de riqueza y también de diferencias entre las naciones, las compañías y las personas.

Era necesario definir la manera europea de transición para esta economía basada en la innovación y en el conocimiento, con marcas distintas — de la salvaguardia de la cohesión social y de la diversidad cultural a las propias opciones tecnológicas. Crear una nueva plataforma competitiva es fundamental para sustentar el modelo social europeo, que también deberá ser renovado.

Este artículo nos trae el debate de los países miembro de la Unión Europea que precedió la Cimera de Lisboa (23-24 Marzo, 2000).

\section{The strategy of Lisbon and its implications for the institutional reform of the European Union}

Maria João Rodrigues

How can the European strategy of development be kept up to date, and under European values, to react to the new challenges decurrent of globalization, technological changes and the aging of populations? Anew paradigm emerges, in which knowledge and innovation are the main sources of wealth and also of differences among nations, companies and people.

It was necessary to define the European way of transition for this economy based on innovation and knowledge, with distinct characteristics - from the safeguard of social cohesion and cultural diversity to the very technological choices. Creating a new competitive platform is fundamental to pay the costs of the European social model, which also must be renewed.

This article brings the European Union member countries debate that preceded the Lisbon Summit (March 23-24, 2000).

\author{
Maria João \\ Rodrigues é \\ professora \\ catedrática no \\ Instituto \\ Superior de \\ Ciências do \\ Trabalho e da \\ Empresa \\ (ISCTE) em \\ Lisboa, \\ Portugal, e \\ conselheira da \\ Comissão \\ Européia para \\ as Políticas \\ Econômicas \\ Sociais. \\ Contato: \\ mariajrodrigues@ \\ iscte.pt
}


